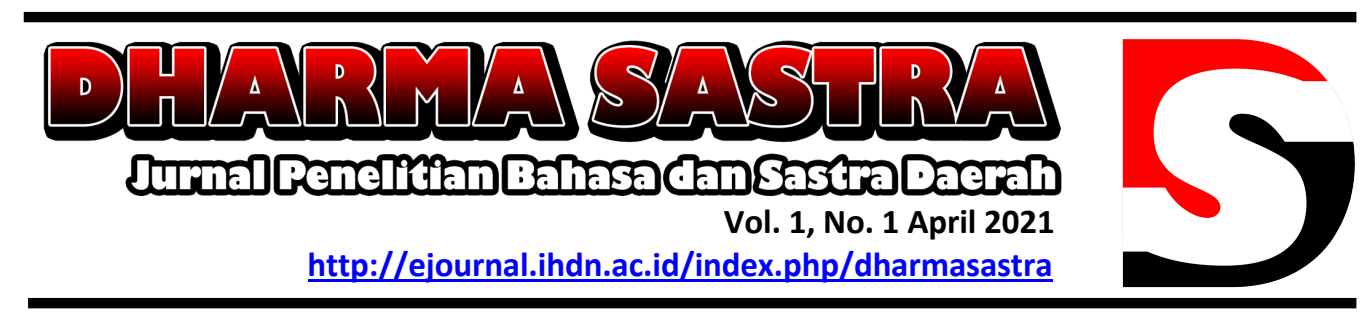

\title{
Ajaran Tri Parartha dalam Kakawin Aji Palayon
}

\author{
Anak Agung Gede Wiraputra
}

UHN IGB Sugriwa Denpasar, Email : agungwira9706@gmail.com

\begin{tabular}{l}
\hline \multicolumn{1}{c}{ Info Artikel } \\
\hline Diterima : 27 Maret 2021 \\
Direvisi : 31 Maret 2021 \\
Diterbitkan : 2 April 2021 \\
Keywords: \\
Literature, Kakawin Aji \\
Palayon, The Journey of \\
Atman, and Tri Parartha. \\
\end{tabular}

\begin{abstract}
Literary work is a life guide of the Balinese Hindu community that still exists until today. One type of traditional Balinese literary work that is rich in moral teachings, especially related to Tri Parartha is kakawin Aji Palayon. This paper seeks to uncover the teachings of Tri Parartha contained in Aji Palayon's kakawin literary work with a set of semiotic and religious theories supported by content analysis and descriptive analysis methods. The results of the analysis show that Kakawin Aji Palayon is a traditional Balinese literary work in the form of a song that tells about the journey of the atman since leaving the rough body until it reaches shunya laya (a place of eternal peace). On the journey the atman is also filled with the teachings of Tri Parartha, namely asih (compassion), punia (sacrifice / sincere gift), and bhakti (truth devotion) which is dominantly found in chapter 1, 3, and 6. With high wisdom and understand the teachings of Tri Parartha well, then the atman can pass through various kinds of obstacles and temptations, so that finally he reaches shunya laya (place of eternal peace).
\end{abstract}

\section{Pendahuluan}

Karya sastra merupakan produk kebudayaan yang masih eksis dibicarakan, diteliti, diulas, maupun dijadikan pedoman hidup bagi masyarakat Nusantara, khususnya masyarakat Bali. Dalam hal ini, karya sastra yang hidup dan berkembang di Bali tidaklah hanya berbahasa Bali saja, namun karya sastra peninggalan kerajaan-kerajaan Hindu Nusantara yang notabena berbahasa Jawa Kuno (Kawi) dan Sanskerta juga tumbuh subur dan menyatu dalam dinamika kebudayaan masyarakat Bali, baik yang tinggal di Bali maupun di daerah transmigrasi. Masyarakat Bali tidak hanya memandang karya sastra sebagai suatu produk ilmu pengetahuan semata, namun esensi yang selalu dipegang oleh keyakinan masyarakat Bali adalah karya sastra merupakan sumber nilai-nilai luhur sebagai alat untuk menuntun serta membimbing menuju kehidupan yang lebih baik atau sering disebut sebagai pangajah-ajah (Suardiana, dkk, 2016: 80). Oleh karena itu, melalui jalur kebudayaan maupun upacara keagamaan, secara tidak langsung masyarakat Bali telah melakukan usaha pelestarian berbagai karya sastra di Bali hingga mampu bertahan di zaman yang serba praktis dan modern seperti saat ini. 
Dalam perkembangannya, karya sastra di Bali merupakan bagian dari kesusastraan Bali, yaitu Kesusastraan Bali Purwa (karya sastra Bali tradisional) dan Kesusastraan Bali Anyar (karya sastra Bali modern). Kesusastraan Bali Purwa adalah kesusastraan Bali yang berbau tradisional atau dalam istilah Balinya disebut susastra tradisi. Kesusastraan Bali Purwa dibagi menjadi dua bagian, yaitu: tembang (puisi Bali tradisional) dan gancaran yang memiliki nama lain prosa Bali tradisional (Suwija, 2014: 83). Kesusastraan Bali Purwa yang berupa tembang dapat dibagi menjadi empat kelompok besar, yaitu: sekar rare (lagu anak-anak tradisional), sekar alit (pupuh), sekar madia (kidung), dan sekar agung (kakawin, sloka, dan palawakya). Keempat kelompok besar tembang diatas disebut dengan Dharmagita. Sekar agung, khususnya kakawin memiliki berbagai macam jenis yang diperuntukkan sesuai dengan tipe upacara dalam agama Hindu yang dikenal dengan istilah Panca Yadnya, yaitu Dewa Yadnya, Rsi yadnya, Pitra Yadnya, Manusa Yadnya, dan Bhuta Yadnya (Sanjaya, 2008: 19). Kakawin berasal dari bahasa Sanskerta, yaitu "kawi" yang berarti "seseorang yang memiliki pengetahuan luar biasa, seseorang yang mampu melihat masa depan, dan seseorang yang bijak". Pada sastra Sanskerta Klasik, istilah "kawi" memiliki arti "penyair". Istilah pada Sanskerta klasik tersebutlah yang diserap ke dalam Bahasa Jawa Kuno sebagai cikal bakal istilah kakawin. Dalam bahasa Jawa Kuno, kakawin berarti puisi berbahasa Jawa Kuno yang diikat oleh aturan irama, matra, rima, serta penyusunan larik dan bait (Zoetmulder dalam Mandra, 2017: 88).

Salah satu jenis kakawin yang sangat unik dan membahas mengenai perjalanan atman atau roh suci setelah lepas dari badan adalah kakawin Aji Palayon. Kakawin Aji Palayon sesuai dengan namanya, yaitu "aji" berarti "ilmu" dan "palayon" (pa + layon, layon adalah jenazah) yang berarti "kejenazahan atau kerohan" merupakan dharmagita yang diperuntukkan pada upacara Pitra Yadnya atau yadnya yang dipersembahkan kepada roh suci leluhur (Gautama, 2009: 369). Kakawin Aji Palayon secara struktur terdiri dari tembang dan terjemahan dimana tembang ditulis dalam bahasa Jawa Kuno ragam sastra (Bahasa Kawi), sedangkan terjemahannya ditulis dalam bahasa Bali. Dalam untaian tembang dan terjemahan ini, kakawin Aji Palayon menyimpan kisah naratif yang sangat mengesankan dan sarat akan nilainilai terkait ajaran kehidupan. Salah satu konsep penting yang termuat dalam kakawin Aji Palayon adalah ajaran Tri Parartha. Tri Parartha merupakan salah satu bagian ajaran etika (susila) Hindu yang memuat tiga bagian, yaitu asih (kasih sayang), punia (pengorbanan/pemberian yang tulus ikhlas), dan bhakti (dharma bhakti). Keutamaan sifat tersebutlah yang dapat menghantarkan sang atman menuju kepada kesempurnaan serta mencapai shunya laya (tempat kedamaian abadi). Berdasarkan uraian tersebut, maka penulis merasa tergugah untuk mengulas ajaran Tri Parartha yang terkandung dalam kakawin Aji Palayon yang dapat dijadikan tuntunan dalam menjalankan kehidupan di dunia ini sebagai bekal untuk perjalanan menuju alam keabadian. Cetusan pemikiran tersebut penulis wujudkan melalui sebuah karya ilmiah berbentuk artikel jurnal ilmiah yang berjudul "Ajaran Tri Parartha dalam Kakawin Aji Palayon".

\section{Metode}

Metode pada dasarnya adalah jalan yang ditempuh oleh seorang peneliti untuk dapat memecahkan masalah dan mengupas tuntas persoalan yang terdapat dalam konten penelitian. Metode dalam artikel ini dibagi menjadi teori, tatacara pengumpulan data, dan pengelolaan data. Teori yang digunakan untuk membedah dua poin pembahasan dalam tulisan yang berjenis kualitatif ini adalah teori struktur dan teori religi. Adapun data penelitian diperoleh dari hasil wawancara, serta studi pustaka yang dikelola dalam teknik analisis data 
berupa reduksi data, display data, serta penarikan kesimpulan. Dengan adanya metode tersebut diharapkan dapat membawa penelitian menjadi terarah dan sesuai dengan prosedur ilmiah.

\section{Pembahasan}

\section{Gambaran Umum Kakawin Aji Palayon}

Dalam kehidupan dewasa ini, sangat banyak peneliti maupun masyarakat awam yang tekun mencari filosofi kehidupan dalam karya sastra serta mulai menggemari karya sastra yang bersifat religius. Banyak orang yang penasaran dengan kehidupan setelah kematian. Salah satu karya sastra yang membahas tentang perjalanan atman atau istilahnya peristiwa pasca kematian adalah Kakawin Aji Palayon yang digunakan oleh masyarakat Bali sebagai nyanyian suci penghantar atman seseorang yang diupacarai dalam upacara Pitra Yadnya. Adapun sinopsis cerita Aji Palayon berawal ketika sang atman keluar dari badan kasarnya, dia melihat banyak saudara dan tetangganya mengelilingi badan kasarnya atau mayatnya dengan segala sarana upacara yang beraneka ragam tertata rapi. Disamping membuat dan mempersiapkan upacara, sang atman melihat banyak orang yang menyanyikan dan melantunkan kakawin Aji Palayon. Ketika dilihatnya sanak saudaranya serta tetangganya, sang atman ingin berbicara kepada mereka semua, tetapi kehendaknya tersebut tidak tercapai. la kemudian masuk ke dalam salah satu orang yang kurus serta lemah tenaganya dan berbicara kepada orang-orang di tempat itu. Dengan meminjam badan orang tersebut, sang atmann kemudian mengatakan kepada para tamu dan sanak keluarganya bahwa jikalau ada kesalahan yang diperbuat oleh sang atman ketika masih hidup, mohon dimaafkan. Sang atman juga berterima kasih kepada orang-orang yang ada di sekitar jasadnya, karena telah menghaturkan persembahan berupa makanan dan sesajen lainnya secara tulus ikhlas. la pun berdoa semoga Tuhan membalaskan budi baik mereka semua. Sebelum pamit, tidak lupa sang atman berterima kasih kepada sang pendeta yang telah membersihkan jiwanya dan berharap semoga Tuhan memberkati sang pendeta yang telah memercikkan air suci kepadanya, sehingga keadaan sang atman menjadi sangat terang dan badan jiwanya menjadi ringan. Ketika sang atman meninggalkan mereka, sadarlah orang yang kesurupan tadi.

Setelah meninggalkan sanak saudaranya, sang atman terbelih dahulu menuju ke sanggah (tempat suci di lingkungan rumah) untuk mengucapkan terimakasih dan juga memohon pamit kepada para leluhur yang telah memberikan rezeki maupun telah menjaganya sampai pada titik tersebut. Sang atman pun direstui sebagai atman yang utama agar dapat mencapai surga loka. Perjalanan selanjutnya, sang atman menuju ke Pura Dalem. Di sana telah menanti Bhatari Durga dengan para hamba-hambanya yang disebut bhuta-bhuti. Bhuta-bhuti mengerumuni sang atman seperti hendak memakannya. Sang atman lari dengan kencangnya karena takut dimakan antek-antek Bhatari Durga tersebut. Ketika sang atman lari, Bhatari Durga bersabda kepada sang atman supaya sang atman jangan takut kepada mereka dan sang atman disuruh diam, karena Bhatari Durga melihat bahwa tidak ada dosa pada diri sang atman. Merasa senanglah hati sang atman mendengar sanjungan Bhatari Durga dan sang atman menyembah Beliau. Tidak lupa sang atman juga memohon kepada Bhatari Durga supaya bermurah hati memberikan ketentraman kepada sanak saudaranya di dunia fana. Setelah diberkati Sang Hyang Durga, sang atman mohon pamit hendak meneruskan perjalanannya ke surga.

Sang atman keluar dari pintu gapura meneruskan perjalanannya ke surga. Tempat yang dituju selanjutnya setelah Pura Dalem adalah Sungai Serayu. Di sana terdapat aliran air yang sangat bening. Ketika sang atman sampai di sungai Serayu, ia berkumur dan mencuci muka. 
Tiba-tiba, munculah seekor buaya yang sangat menakutkan dan hendak menerkam sang atman. Sang atman pun dengan cepat menghindarkan dirinya dari terkaman sang buaya. Setelah terhindar dari terkaman buaya, sang atman berkata pada sang buaya bahwa sesungguhnya sang buaya merupakan adik sang atman yang berasal dari ari-arinya. Setelah diberikan ujaran oleh sang atman, sang buaya diam dan menurut kepada sang atman, bahkan sang buaya menyediakan dirinya untuk menyebrangkan sang atman ke seberang sungai. Sesampai di seberang sungai, di sana sudah menanti seorang raksasa wanita bertampang mengerikan yang bernama Raksasa Sirsa. Dengan tidak merasa segan sang atman segera maju dan berbicara dengan lemah lembut kepada sang raksasa wanita. Akhirnya, sang raksasa mengakui kelebihan sang atman. Setelah memberi hormat kepada sang atman, raksasa wanita itu memutar tubuhnya dan lari meninggalkan sang atman. Setelah terbebas dari raksasa wanita yang mengerikan, sang atman bersujud dan berdoa lalu meneruskan perjalanannya menuruni lereng gunung yang curam. Di sana sang atman bertemu dengan macan merah yang mau menerkamnya. Dengan kelebihan dan pengetahuannya, sang atman berhasil menaklukkan sang macan merah dengan memberikan petuah bahwa sang macan adalah sudaranya, yaitu darah yang lahir bersama dengan sang atman sewaktu dulu. Sang macan pun menggoyang-goyangkan ekornya dan menuruti kata-kata sang atman, lalu pergi menjauhi sang atman.

Setelah melewati beberapa rintangan, sang atman meneruskan perjalanannya sambil menari dan melompat-lompat. Kegembiraan sang atman mempengaruhi para penghuni hutan lainnya yang ikut bersuka ria. Kegembiraan sang atman tidak berlangsung lama karena sang atman dihadang oleh anjing hitam yang tinggi dan besar. Dengan tutur katanya, sang atman berhasil meyakinkan anjing tersebut, sehingga sang anjing hitam mundur dan menunduk, bahkan hingga berlinang air mata akibat tutur kata sang atman. Diceritakan sang atman kembali melanjutkan perjalanan hingga sampai di suatu tempat dengan air yang sangat bening. Ketika itu waktu telah tengah malam dan sang atman hendak mencuci muka. Ketika sang atman akan berteduh, ia dikejutkan oleh adanya gemuruh suara yang sangat menakutkan. Suara tersebut berasal dari sang Butakala yang telah tiga hari tiga malam tidak menyantap makanan dan kebetulan bertemu dengan sang atman. Dengan rasa ketakutan, sang atman berkata halus kepada sang Butakala bahwa sang Butakala dianjurkan datang ke rumah sang atman karena di sana telah disediakan makanan yang beraneka ragam. Sang Butakala lalu pergi menuju tempat sang atman untuk menyantap sesaji yang disediakan keluarga sang atman.

Rintangan yang menghadang sang atman masih berkelanjutan. Pada perjalanan selanjutnya, sang atman dihadang oleh empat Butakala yang sangat menakutkan, yaitu Sang Anggapati, Sang Prajapati, Sang Banaspati dan Sang Banaspatiraja. Keempat Butakala tersebut akan memangsa sang atman. Dengan segala pengetahuannya, sang atman akhirnya dapat menganjurkan keempat Butakala pergi ke rumah sang atman karena ada sesaji untuk disantap. Sang atman pun kembali melanjutkan perjalanannya. Suasana yang tenteram dihiasi oleh taman bunga di sepanjang jalan mengiringi perjalanan sang atman. Di tengah-tengah taman bunga yang indah tersebut, terdapat sebuah pemandian yang indah sekali serta jernih airnya. Tempat itu bernama Pancaka Tirta dan disitulah yang menjadi tujuan sang atman. Di sana sang atman segera berkumur dan mandi. Setelah berkumur dan mandi, badan sang atman manjadi bersinar seperti emas. Sang atman kemudian disongsong oleh para Dewata dan bidadari. Dengan pakaian dan perhiasan yang indah serta disinari sinar bulan, para Dewata dan bidadari menyongosong sang atman dengan tandu emas yang berkilauan. Mereka mengiringi sang atman menuju ke surga. Sesampainya di surga, Dewata dan bidadari 
lalu membawa sang atman untuk menghadap Ida Sang Hyang Widhi Wasa. Sang atman bersujud bhakti dan mengucapkan puji syukur karena ia diberikan kekuatan serta keteguhan untuk mencapai surga. Ida Sang Hyang Widhi Wasa kemudian memberkahi serta memberikan tugas kepada sang atman untuk selalu menegakkan kebenaran.

\section{Ajaran Tri Parartha dalam Kakawin Aji Palayon}

Kakawin Aji Palayon merupakan karya sastra berbahasa Jawa Kuno yang sarat akan nilai etika atau susila. Adapun dasar dari susila itu sendiri tiada lain adalah kebajikan, kesetiaan, hukum-hukum kehidupan, kekuatan bathin, kekayan rohani, serta ketekunan (Sudharta, 2009: 71). Salah satu ajaran susila yang sangat lekat dengan keberadaan kakawin Aji Palayon adalah ajaran Tri Parartha. Tri Parartha berasal dari bahasa Sanskerta, yaitu dari kata tri artinya tiga dan parartha artinya kebahagian atau kesejahteraan. Tri Parartha artinya tiga jenis perilaku yang dapat mewujudkan kebahagian dan kesejahteraan (Susila dan Mulia, 2015: 2). Bagian-bagian dari Tri Parartha yaitu asih (kasih sayang), punia (pengorbanan/pemberian yang tulus ikhlas), dan bhakti (dharma bhakti). Ajaran Tri Parartha telah merasuk dan menjiwai setiap jengkal perjalanan sang atman utama dalam kakawin Aji Palayon, sehingga pada akhirnya mampu mencapai tujuan tertinggi yang dinamakan suka tan pawali duka (kebahagiaan yang tidak akan kembali menuju kesengsaraan). Adapun ajaran Tri Parartha dalam kakawin Aji Palayon dapat diuraikan dalam pembahasan di bawah ini.

\section{a. Asih (Kasih Sayang)}

Perilaku asih adalah perilaku menyayangi, mengasihi seluruh makhluk hidup dan juga peduli lingkungan. Peduli lingkungan merupakan salah satu penerapan perilaku asih karena dengan menumbuhkan sikap peduli, akan menumbuhkan rasa cinta dan kasih sayang terhadap semua ciptaan Tuhan. Perilaku asih dapat menyebabkan kerukunan, kedamaian, dan keharmonisan sehingga mampu saling asah (harga-menghargai), saling asih (cinta mencintai), saling asuh (hormat-menghormati) sesama teman dan sesama makhluk hidup (Sumartawan, 2007: 47). Asih dalam kakawin Aji Palayon dapat dilihat dalam pembahasan sebagai berikut.

\section{1) Sargah 1, Bait ke 8 dan 9}

Ajaran asih yang terdapat pada sargah 1, bait ke 8, 9, dan 10 diuraikan sebagai berikut:

"Sang asih amrih angarih arih,

Ri asihnya ring sang kasyasih,

Lingnya mandra mredu alindi,

Kadhawuhaken ring mahā kurunganya" (Kakawin Aji Palayon Sargah 1, bait ke 8).

Terjemahan:

Sang atman dengan penuh kasih sayang berusaha untuk meyakinkan, karena sayangnya kepada yang ingin diyakinkan, perkataannya halus dan lemah lembut, diucapkan kepada badan kasar atau raganya.

"Ah udhuh mahā rungkingku,

Sthanangku angaji ring nguni,

Aśramangku kita tāmoli,

Tān lalya aku ri karuṇānta" (Kakawin Aji Palayon Sargah 1, bait ke 9).

Terjemahan: 
Wahai engkau raga jasmaniku, tempatku menempa diri dan belajar dari dulu, engkau tiada lain adalah tempatku dan sthanaku, aku tidak akan pernah lupa dengan cinta kasihmu.

Kutipan sargah 1, bait ke 8 dan 9 pada kakawin Aji Palayon di atas menggambarkan betapa sayangnya sang atman kepada badan jasmaninya yang akan ditinggalkan. Dengan suara yang lemah lembut, sang atman menunjukkan betapa sayangnya ia dengan badan kasarnya. Sang atman sangat menyayangi badan kasarnya karena badan kasarnya tersebut merupakan tempatnya bersthana dari sejak dilahirkan hingga sang atman akan kembali kepada pencipta. Badan kasar atau badan jasmaninya tersebut juga meupakan tempat sang atman mempelajari berbagai hal di dunia, sehingga ia mengetahui dan mengecap manis pahitnya kehidupan dunia. Oleh karena itu sang atman sampai kapanpun tidak akan pernah melupakan jasa dari badan jasmaninya serta tentunya sangat menyayangi badan kasarnya. Dalam hal ini, perilaku sang atman menunjukkan bahwa ia tidaklah seperti kacang yang lupa akan kulitnya. la sangat menghargai dan berterimakasih kepada badan kasarnya yang sangat berjasa besar hingga ia sampai kepada tahap dimana ia harus meninggalkan badan kasarnya, namun cinta kasihnya tidaklah pernah pudar serta ia berharap bisa bertemu kembali di kehidupan mendatang.

\section{2) Sargah 1, Bait ke 30, 31, dan 32}

Ajaran asih yang terdapat pada sargah 1, bait ke 30, 31, dan 32 diuraikan sebagai berikut:

"Sahayangku kita prasama

Tar malupa aku ri anuraganta

Moga kita olih asaněm

Dhaněmbaksa němkalihaněm" (Kakawin Aji Palayon Sargah 1, bait ke 30).

Terjemahan:

Wahai saudaraku semua, aku tidak akan pernah lupa dengan kasih sayangmu. Semoga engkau semua selalu mendapatkan kesehatan, kemakmuran, dan lain sebagainya.

"Tan kawaśa aku ngawantunaken,

Asih ta ri pușpaka minī,

Anghing buddhi susatya juga,

Panwalku rī sukīrtinta" (Kakawin Aji Palayon Sargah 1, bait ke 31).

Terjemahan:

Tidak akan pernah bisa aku membalas, rasa cinta kasih saudara sekalian kepadaku, tetapi hati yang setia, sebagai saranaku membalas semua cinta kasih saudara sekalian.

\section{"Rapuan sang Hyang Parama Kawi \\ Anugraha kadirgayusan \\ Ri saranangku makabehan \\ Apan kita sulaksana" (Kakawin Aji Palayon Sargah 1, bait ke 32). \\ Terjemahan: \\ Semoga Tuhan Yang Maha Esa, selalu memberikan umur yang panjang, kepada saudaraku sekalian, karena engkau sekalian telah berbuat baik terhadapku.}

Penggalan kakawin Aji Palayon diatas menceritakan tentang sang atman yang sudah meninggalkan badannya dan mencari perantara untuk berbicara kepada sanak saudaranya 
yang masih hidup. Setelah mendapatkan perantara untuk berkomunikasi dengan meminjam tubuh seorang yang kurus, sang atman menyampaikan rasa terima kasih kepada seluruh sanak saudara karena telah mencintai dan menyayangi sang atman semasih hidup serta telah mengupacarai badan kasar sang atman dengan baik setelah ia meninggal. Tidak lupa sang atman juga mendoakan agar semua sanak keluarganya tersebut selalu diberikan kesehatan, kemakmuran, serta berbagai anugerah lainnya. Hal ini menunjukkan konsep asih yang sejati, karena sang atman benar-benar merasakan hangatnya kasih sayang dari seluruh sanak sudaranya, baik saat masih hidup maupun setelah meninggal, sehingga akan menjadi kesan yang tak terlupakan serta karma baik yang dilakukan oleh sanak keluarganya akan senantiasa dikembali berupa pahala yang baik oleh Tuhan Yang Maha Esa.

\section{b. Punia (Pengorbanan/Pemberian yang Tulus Ikhlas)}

Perilaku punia adalah perilaku saling menolong kepada sesama untuk menumbuhkan cinta kasih, seperti memberikan sesuatu atau benda yang dimiliki tanpa pamrih, berbagi pengetahuan, berbagi kesenangan, dan berguna bagi yang membutuhkan. Berdana punia dengan dasar keikhlasan, tanpa pamerih dan tidak dengki merupakan bentuk keteguhan sradha dalam berbuat kebajikan, sehingga selalu selamat dan mendapatkan pahala yang setara dengan beryadnya (Gun-gun, 2012: 210). Punia dalam kakawin Aji Palayon dapat dilihat dalam pembahasan sebagai berikut.

\section{1) Sargah 3, Bait ke 45, 46, dan 47}

Ajaran punia yang terdapat pada sargah 3, bait ke 45, 46, dan 47 diuraikan sebagai berikut:

"Apanakweki maawak àtma,

Śunyahastan aku dhateng atra,

Dhatenga kita ri humahku,

Hanekā saji cumadhang hanengkana" (Kakawin Aji Palayon Sargah 3, bait ke 45).

Terjemahan:

Karena aku beragakan atman, aku hanya membawa tangan kosong kesini, pergilan

engkau sekalian ke rumahku, di sana terdapat upakara yang sudah disediakan.

"Bubur pirata Sang Bāwal nanggap,

Sekar ura ri Sang Mrajasela,

Sega tepeng Sang Badmoti nadhah,

Panjangilang Sang Bādpamiad polih"(Kakawin Aji Palayon Sargah 3, bait ke 46).

Terjemahan:

Bubur pirata diterima oleh Sang Bawal, sekar ura adalah untuk Sang Mrajasela, nasi bubur dimakan oleh Sang Badmoti, dan panjangilang adalah dipersembahkan kepada Sang Badpamiad.

"Para pawewehku ring sang kredha,

Segā wingkisan lawan katupat,

Pangangkatangkat Sang Gridig nampi,

Iwak itik madhya Sang Jigrug mananggāp" (Kakawin Aji Palayon Sargah 3, bait ke 47).

Terjemahan: 
Selain itu persembahanku kepada Sang Kredha, nasi takilan dan ketupat, pangangkatangkat diterima oleh Sang Gridig, daging itiknya Sang Jigrug yang mendapatkan.

Berdasarkan kutipan kakawin Aji Palayon sargah 3 bait ke 45, 46, dan 47 di atas, terlihat bahwa sang atman dalam perjalanannya menuju ke surga tidaklah berbekal apa-apa. Hanyalah pengetahuan dan tekad yang bulat menjadi bekalnya sepanjang perjalanan. Saat ia dihadang oleh bhuta kala yang bernama Sang Bawal, Sang Badpamiad, Sang Mrajasela, dan Sang Badmoti yang sangat lapar dan sudah bersiap-siap menerkam sang atman, maka sang atman pun mengatakan dengan jujur bahwa ia tidak berbekal apa-apa. Namun, ia menawarkan kepada seluruh bhuta kala tersebut bahwa meskipun sang atman tidak membawa apa-apa, tetapi di rumahnya telah tersedia berbagai macam upakara atau sarana upacara yang penuh dengan persembahan berupa makanan maupun minuman untuk para bhuta kala. Sang atman pun memberikan petunjuk terkait nama bhuta kala dan sarana yang mana diperuntukkan kepada bhuta kala tersebut. Otomatis sang bhuta kala pun dengan riangnya menuju ke kediaman sang atman. Dalam hal ini, punia sang atman serta sanak keluarga sang atman sangatlah terlihat dari ketulusikhlasan untuk menghaturkan pengorbanan yadnya tulus ikhlas berupa berbagai kelengkapan upakara pratekaning layon, sehingga sang bhuta kala mendapatkan upacara yang tepat serta akhirnya tidak mengganggu perjalanan sang atman menuju tempat kedamaian abadi.

\section{2) Sargah 3, Bait 58}

Ajaran punia yang terdapat pada sargah 3 , bait ke 58 dapat diuraikan sebagai berikut:

"Kaka ang Surātma Jogor Manik, Iriki ta ang Mahā Kala Dora Kala, Lumakwa kita ka kuwungku nguni, Rikana hana tarpana cumadhang" (Kakawin Aji Palayon Sargah 3, bait ke 58). Terjemahan:

Wahai kakakku Sang Suratma dan Jogor Manik, adikku Sang Maha Kala dan Dora Kala, pergilan engkau menuju ke rumahku, di sana telah disiapkan upacara berupa caru tarpana untuk engkau sekalian.

Dalam uraian kakawin Aji Palayon sargah 3 bait ke 58 di atas, diceritakan bahwa dalam perjalanannya, sang atman kembali dicegat oleh Sang Suratma, Sang Jogor Manik, Sang Maha Kala, dan Sang Dora Kala yang tidak lain adalah saudara yang mengiringi sang atman saat dilahirkan ke dunia. Sang atman pun menjelaskan bahwa beliau adalah keempat saudara sang atman serta menawarkan keempat saudaranya itu untuk menuju rumah sang atman, karena di sana telah disipkan sarana upacara berupa caru tarpana untuk mereka berempat. Keempat saudara sang atman itupun berterimakasih dan segera bergegas menuju ke rumah sang atman, sehingga mereka tidak mengganggu perjalanan sang atman. Dalam uraian tersebut, ajaran punia kembali terlihat dari siap siaganya keluarga sang atman menyediakan serta menyiapkan pengorbanan suci berupa caru tarpana untuk catur sanak (keempat saudara) sang atman. Ketulusikhlasan pengorbanan tersebut merupakan bentuk punia suci kepada catur sanak sang atman agar senantiasa perjalanan sang atman menuju ke keabadian dapat berjalan dengan lancar.

\section{3) Sargah 6, Bait ke 20 dan 21}


Ajaran punia yang terdapat pada sargah 6, bait ke 20 dan 21 dapat diuraikan sebagai berikut:

"Gotrangku lan sahananing atiti prasamya, Gung tūhwasihta kadi gung bhuwanā sama tui, Sang Hyang Widhĩ Wasa amoga maweh subhoga, Nā Iwir ujar kiwara ātma awas karungwa" (Kakawin Aji Palayon Sargah 6, bait ke 20). Terjemahan:

Saudara-saudaraku serta serta para tamu sekalian, benar-benar besar kasih sayangmu sekalian bagaikan besarnya dunia, semoga Tuhan selalu menganugerahi kemakmuran, demikian perkataan sang atman yang terdengar dari kejauhan.

"Gotrang ki ātma kalawan atiti prasāmya, Lingnyā tisāda rarisang jiwa ātma maśuddhā, Ah oh ki ātma suci astu kiteki māngguh, Unggwan sudiwya kita sestu uceng sāparan" (Kakawin Aji Palayon Sargah 6, bait ke 21).

Terjemahan:

Sanak saudara sang atman dan para hadirin semuanya, perkataannya sangatlah manis tertuju kepada sang atman yang maha suci, wahai engkau sang atman suci semoga engkau mendapat tempat yang utama, dan senantiasa mampu mencapai tujuan adi luhur.

Penggalan kakawin Aji Palayon sargah 6 bait 20 dan 21 di atas menceritakan tentang doa yang disampaikan oleh sang atman kepada sanak saudaranya agar selalu dilimpahkan berbagai bentuk kemakmuran sebagai balasan cinta kasihnya terhadap sang atman. Hal tersebut dibalas dengan doa sanak keluarga dan para tamu kepada sang atman agar sang atman mampu mencapai keutamaan dan mampu mencapai tempat kedamaian abadi. Ajaran punia yang terkandung dalam kutipan tersebut dapat terlihat dari ketulusikhlasan saling mengirim persembahan berupa doa yang tulus ikhlas antara sang atman dan sanak saudaranya. Meskipun terlihat sepele, punia berupa doa yang tulus ikhlas merupakan persembahan yang utama, karena dengan ketulusan hati dan keikhlasan jiwa, maka Tuhan akan senantiasa mendengarkan dan mengabulkan doa tersebut.

\section{c. Bhakti (Dharma Bhakti)}

Perilaku bhakti adalah perilaku hormat dan menyayangi. Perilaku bhakti merupakan berbuat dengan tulus hati. Perbuatan dharma yang dilakukan setulus hati merupakan salah satu jalan kebaikan yang dinamakan Bhakti Marga Yoga, baik kepada orang tua, para guru, orang suci, pemerintah, maupun Ida Sang Hyang Widhi Wasa. Melakukan hal-hal tersebut di atas akan mengantarkan pada pencapaian kehidupan yang bahagia (Susila dan Mulia, 2015: 4). Ajaran bhakti yang terdapat dalam kakawin Aji Palayon dapat dilihat dalam pembahasan sebagai berikut.

\section{1) Sargah 1, Bait ke $\mathbf{4 9}$ dan 50}

Ajaran bhakti yang terdapat pada sargah 1, bait ke 49 dan 50 diuraikan sebagai berikut:

"Sembahing wwang manembah,

Dudug mareng byomantara,

Lwir wịnā mredhukomala, 
Angawe tușța ri sang ātma" (Kakawin Aji Palayon Sargah 1, bait ke 49).

Terjemahan:

Sembah bhakti para sanak keluarga yang menghaturkan bhakti, terbang melayang ke langit, seperti suara rebab yang merdu dan mengesankan, membuat hati sang atman menjadi senang dan bahagia.

"Garjita sang warātma,

Ngarengöku ning pūjā,

Kaworan śoka mānasa,

Alah asihnya ri sang kari" (Kakawin Aji Palayon Sargah 6, bait ke 50).

Terjemahan:

Sangatlah bahagia hati sang atman, mendengar seluruh doa dari sanak keluarga, bercampur dengan rasa sedih, karena cinta kasih yang begitu mendalam kepada keluarga yang masih hidup.

Kutipan kakawin Aji palayon sargah 1 bait ke 49 dan 50 di atas telah menunjukkan bahwa begitu bhaktinya sanak keluarga memanjatkan doa kepada Sang Pencipta untuk pencapaian keutamaan sang atman, sehingga sang atman merasa sangat terharu dan bahagia. Doa tersebut dilandasi oleh rasa bhakti dan sayang kepada sang atman, sehingga kebahagiaan sang atman bercampur haru dan sedih karena harus meninggalkan sanak keluarganya. Ajaran bhakti tersebut sangatlah kentara dari ketulusan sanak keluarga menunjukkan bhakti dan penghormatan kepada sang atman dengan jalan menyiapkan korban suci sebagai kelengkapan upacara serta dengan penuh sujud mendoakan sang atman agar mendapatkan dan mencapai tempat kedamaian abadi. Dengan adanya bhakti tersebut, maka akan senantiasa timbul ikatan kasih sayang yang tiada batas, baik dalam diri sang atman maupun sanak keluarganya.

\title{
2) Sargah 3, Bait ke 12, 14, dan 15
}

Ajaran bhakti yang terdapat pada sargah 3, bait ke 12, 14, dan 15 diuraikan sebagai berikut:

\author{
"Ah ah kita sang Jagulagung \\ Hayua kita angawit lampahku \\ Kita antěnku tan hana len \\ Ari-ari ika pawakna" (Kakawin Aji Palayon Sargah 3, bait ke 12). \\ Terjemahan:
}

Wahai engkau sang buaya besar, janganlah engkau menghalangi perjalananku. Engkau tiada lain adalah saudaraku. Engkau adalah penjelmaan ari-ari yang mengiringiku pada saat aku dilahirkan.

"Aringku kita sang jagul agung,

Pundhuta kakanta angentas nadī,

Rapwan bramaga wawang limpad,

Sangkeng Iwah atiwi śala iki" (Kakawin Aji Palayon Sargah 3, bait ke 14).

Terjemahan:

Wahai adikku sang buaya besar, gendonglah kakakmu ini untuk melewati aliran sungai, agar segera bisa menyeberangi, sungai yang sangat dalam ini.

"Sang kinon agya mangsö sādara, 
Sumūngaken gigirnya ri sang kaka,

Sang ātma munggah ri walakang sang jagul,

Śighra sira tumekeng pasir" (Kakawin Aji Palayon Sargah 3, bait ke 15).

Terjemahan:

Buaya yang diperintahkan dengan cepat bergerak, memberikan punggungnya kepada sang kakak, sang atman duduk di atas punggung buaya, dengan cepat sang atman sampai di seberang sungai.

Dalam kutipan kakawin Aji Palayon sargah 3 baik 12, 14, dan 15 di atas mengisahkan tentang perjalan sang atman yang dihadang oleh buaya besar. Kemudian berbicaralah sang atman tersebut kepada sang buaya, bahwa sang buaya tersebut merupakan salah satu perwujudan saudaranya yang mengiringinya lahir kedunia. Saudara yang dimaksud adalah ariari yang memberikan asupan nutrisi pada cabang bayi di dalam rahim. Dalam hal ini, peristiwa yang di alami oleh sang atman inilah sebagai bukti bahwa ketika kita sudah meninggal, saudara yang kita ajak bersama saat lahir bisa berubah menjadi wujud yang mengerikan. Setelah sang atman menjelaskan kepada buaya besar tersebut, secara mendadak buaya tersebut menjadi sadar dan menurut kepada kakaknya yang tiada lain adalah sang atman itu sendiri. Akhirnya buaya besar tersebut mengantarkan kakaknya menuju ke seberang sungai dengan penuh bhakti. Adapun ajaran bhakti dalam penggalan kakawin tersebut terlihat dari ketulusikhlasan buaya besar tersebut dengan penuh rasa bhakti memberikan punggungnya kepada sang kakak (sang atman) dan bersedia dengan setulus hati menyeberangkan kakaknya tersebut hingga ke seberang sungai.

\section{3) Sargah 3, Bait ke 35, 36, dan 37}

Ajaran bhakti yang terdapat pada sargah 3, bait ke 35, 36, dan 37 diuraikan sebagai berikut:

\footnotetext{
"Nahan ling sang atma ati prayadna

Hana sambra irěng katon mangsa

Agung aluhung luir adri anak

Sinongan Hyang Hima megha akanděl" (Kakawin Aji Palayon Sargah 3, bait ke 35)

Terjemahan:

Demikianlah perkataan sang atman yang sangat waspada. Dilihatlah seekor anjing hitam yang siap-siap untuk menerkamnya. Anjing itu sangatlah tinggi dan besar, bagaikan anak gunung. Anjing tersebut berpayungkan kabut dan mendung.
}

\section{"E sang asu irěng sadulurku}

Yeh nyom ika pawakna ta nguni

Kita parěng metu lawan aku

Ningkira kita sangkeng awangku" (Kakawin Aji Palayon Sargah 3, bait ke 36)

Terjemahan:

Wahai engkau sang anjing hitam, engkau tiada lain adalah penjelmaan dari air ketuban. Engkau dan aku sama-sama lahir dari satu rahim. Minggirlah engkau dari jalanku.

"Sang wreka kresna tulwi angrepa

Anarawata luhnya marabas

Dinilat astan Sang Jiwatma 
Terjemahan:

Anjing hitam yang besar tersebut kemudian jongkok, air matanya berlinang, lalu ia menjilat-jilat tangan sang atman, ekornya bergoyang-goyang lalu pergi meninggalkan sang atman.

Kutipan kakawin Aji Palayon sargah 3, bait ke 35, 36, dan 37 di atas menjelaskan bahwa anjing hitam besar yang menakutkan dan ingin memakan sang atman akan berubah menjadi jinak, bahkan menangis saat diceritakan hakikat hubungan yang terdapat di antara mereka berdua, yaitu sebagai kakak adik. Sang Anjing adalah air ketuban yang menjadi pelicin agar sang bayi (atman) dapat lahir ke dunia dengan selamat. Cerita asal-usulnya dengan sang atman membuat anjing hitam tersebut meneteskan air mata dan senantiasa mendoakan sang kakak agar dapat menuju ke surga loka. Sang anjing pun segera menjilat-jilat tangan sang atman, mengibaskan ekornya, serta mempersilahkan sang atman untuk berjalan sebagai wujud sujud bhakti seorang adik yang tidak mau menghalangi perjalanan sang kakak. Uraian di atas telah membuktikan rasa bhakti yang luar biasa antara saudara yang dipisahkan dalam waktu yang sangat lama, sehingga saat bertemu kembali dan diceritakan asal-usulnya, maka akhirnya luapan tangis pun terjadi dan dengan penuh kesadaran akan tergerak keinginan untuk saling membantu dengan tulus ikhlas. Begitulah bhakti anjing hitam yang ingin agar kakaknya (sang atman) mendapatkan kemuliaan.

\section{Kesimpulan}

Kakawin Aji palayon merupakan karya sastra yang kaya akan nilai-nilai etika di dalamnya. Salah satu ajaran etika yang sangat mengakar dalam kakawin ini adalah ajaran Tri Parartha, yaitu asih (kasih sayang), punia (pengorbanan/pemberian yang tulus ikhlas), dan bhakti (dharma bhakti). Ketiga hal tersebut mengiringi perjalanan sang atman dari awal melepas badan kasarnya hingga akhirnya mencapai tepat yang disebut dengan shunya laya (tempat kedamaian abadi). Hal kunci yang dapat membuat sang atman mampu mencapai kedamaian abadi adalah kesadarannya akan pengetahuan suci berlandaskan Tri Parartha, sehingga selama perjalanan ia mampu mengatasi berbagai bentuk rintangan, ancaman, serta bahaya dengan baik dan penuh dengan ketenangan.

Pada kehidupan modern seperti saat ini, hendaknya tradisi membaca dan menembangkan kakawin, khususnya kakawin Aji Palayon dalam upacara Pitra Yadnya senantiasa digalakkan ke ranah generasi muda, karena kakawin ini mengandung sangat banyak ajaran susila di dalamnya, salah satunya Tri Parartha yang mampu menghaluskan batin generasi muda, sehingga tidak mudah tersulut emosi apabila menemui masalah serta mampu meneladani jejak sang atman utama yang selalu mawas diri dan memahami masalah dengan kesadaran penuh sebelum menyelesaikannya.

\section{Daftar Pustaka}

Gautama, Nyoman Budha. 2009. Kamus Bahasa Bali (Bali-Indonesia). Surabaya: Paramita. Gun Gun, 2012. Bhagavad Gita Terjemahan Bergambar. Denpasar: ESBE.

Mandra, I Wayan. 2017. Esensi Kakawin Dalam Masyarakat Bali, Vol. 7. Denpasar: IHDN Denpasar.

Mardiwarsito. 1986. Kamus Jawa Kuna-Indonesia. Flores: Nusa Indah.

Sanjaya. 2008. Acara Agama Hindu. Surabaya: Paramita. 
Sekaa Wirama Santi Sastra Komala. 1999. Aji Palayon (Kakawin Miwah Tegesipun, Mangge Rikala Pitra Yadnya). Denpasar: Fakultas Sastra Universitas Udayana.

Suardiana, dkk. 2016. Udiana Sastra SMA/SMK Kelas X. Denpasar: Dinas Pendidikan Pemuda dan Olahraga Provinsi Bali.

Sudharta. 2009. Sarasamuccaya Smerti Nusantara (Berisi Kamus Jawa Kuno-Indonesia). Surabaya: Paramita.

Susila dan Mulia. 2015. Pendidikan Agama Hindu dan Budi Pekerti. Jakarta: Kementerian Pendidikan dan Kebudayaan.

Suwija. 2014. Widia Sari (Basa lan Sastra Bali 3). Denpasar: Sri Rama.

Sumartawan, I Ketut., Ed. Supriadi, Ida Bagus Putu. 2007. Buku Pelajaran Agama Hindu Kelas III. Denpasar: Widya Dharma. 